\title{
Numerical Analysis with Experimental Validation of Single-Phase Fluid Flow in a Dimple Pattern Heat Exchanger Channel
}

\author{
Urban Močnik ${ }^{1,2}$ - Bogdan Blagojevič ${ }^{3}$ - Simon Muhič ${ }^{1,4, *}$ \\ ${ }^{1}$ University of Novo mesto, Faculty of Mechanical Engineering, Slovenia \\ 2Danfoss Trata d.o.o., Slovenia \\ 3Plinovodi d.o.o., Slovenia \\ ${ }^{4}$ SIMUTEH s.p., Slovenia
}

\begin{abstract}
A plate heat exchanger with a dimple pattern heat plate has a large number of dimples. The shape of dimples defines the characteristics of the plate heat exchanger. Although such heat exchangers have become increasingly popular due to their beneficial characteristics, knowledge of the flow characteristics in such kind of channel is poor. A good knowledge of the flow conditions inside of such channel is crucial for the successful and efficient development of new products. In this paper single-phase water flow in dimple pattern plate heat exchanger was investigated with application of computational fluid dynamics and laboratory experiments. Numerical analysis was performed with two turbulence models, Realizable $k-\varepsilon$ with enhanced wall treatment function and $k-\omega$ SST. The first predicts a slightly smaller pressure drop and the second slightly larger compared to the results of laboratory measurements. Our research found that despite the relatively low velocity of the fluid, turbulent flow occurs in the channel due to its shape. We also found that there are two different flow regimes in the micro plate heat exchanger channel. The first regime is the regime that dominates the heat transfer, and the second is the regime where a recirculation zone appears behind the brazing point, which reduces the surface for heat transfer. The size of the second regime does not change significantly with the velocity of the fluid in the volume considered.
\end{abstract}

Keywords: heat exchanger, dimple pattern, pressure drop, computational fluid dynamics, turbulence models
Highlights
- We carried out measurements of the pressure drop in channel formed by two dimple pattern heat plates of heat exchanger by a novel measuring method which allows direct comparison.
- $\quad$ We presented a comprehensive analysis of the flow state in a plate heat exchanger with a dimple pattern heat plate structure.
- We addressed the differences in CFD results between two major turbulence models.
- We proposed the computational mesh structure to achieve a fair ratio between accuracy and computational resources.

\section{INTRODUCTION}

A heat exchanger is a device that allows the transfer of heat between two or more liquids of different temperatures. Heat exchangers are useful in many systems in the industry and they are also widely represented in district heating systems. A plate heat exchanger is a type of heat exchanger in which hot and cold fluids are separated by a thin wall. These walls have a characteristic corrugated shape and are called heat plates. There can be several hundred thin walls in one plate heat exchanger where each of the other heat plate faces the opposite direction, forming a channel in which there is water flow. This creates a number of channels, half of which are connected to the primary and half to the secondary plate. The heat plates are made of stainless steel. Bonding material, most often copper, leaks into the edges of the product due to the capillary effect and forms a seal in a vacuum furnace. At the same time, copper also flows into the junctions of the plates, where it forms the joints referred as brazing points.
The design of the heat plates determines the characteristics of the heat exchanger. Worldwide, the most popular type of plate is so called fishbone or chevron shape. These plates are shaped as shown in Fig. 1a. The angle and depth of the corrugations determine the characteristics of the heat exchanger. Products with such a plate are simply referred to as brazed plate heat exchangers (BPHE). This type of heat exchangers, with some improvements, have been in use since the 1970s [1].

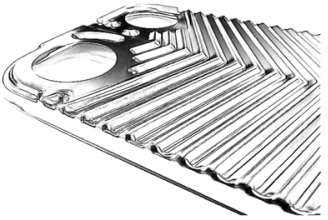

a)

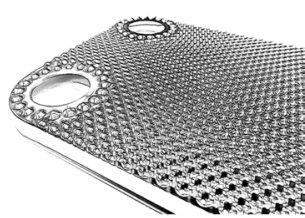

b)
Fig. 1. a) The fish bone pattern heat plate, and b) dimple pattern heat plate

Recently however, a new heat plate design has emerged that significantly improves the characteristics 
of heat exchangers. New structure of the plate does no longer have straight corrugations, but a large number of dimples, which is why it is called a dimple pattern. The shape of dimples defines the characteristics of this type of heat exchanger. The dimple pattern heat plate is shown in Fig. $1 \mathrm{~b}$.

While there is widely available literature about the fluid flow through a duct in the field of BPHE, there is no available literature of dimple pattern type heat exchangers. The flow of liquid at a micro-level is very difficult to observe in the heat exchanger due to small channels and the diverse structure [2]. Some have succeeded to some extent, for example Focke and Knibbe [3]. But with the spread of computational fluid dynamics (CFD) researchers finally got a useful tool to investigate fluid flow conditions inside plate heat exchangers. In the beginning, they first studied flows in two dimensions, just like Metwally and Manglik [4]. They investigated the distribution of flow and temperature, friction factor and the Nusselt number in the sinusoidal fraction of the heat exchanger channel. Kanaris et al. [5] has used more geometry and observed similar phenomena. With the increasing capacity of computers, scientists have been able to start studying the entire BPHE channel. Han et al. [6] analysed a few consecutive channels and observed the heat transfer and flow distribution. Their numerical results deviated from the laboratory at some points up to $35 \%$, but some uncertainty was attributed also to the laboratory experiment. Gherasim et al. [7] used a computer-modelled model of two BPHE plates in their calculations, but excluded the geometry of the distribution channel and instead predicted a uniform distribution of fluid flow velocity at the inlet and outlet in the channel between the plates. They calculated the case with different turbulence models at different flow velocities. The closest results compared to experimental results were achieved with Realizable $k-\varepsilon$ turbulence model with Non-equilibrium wall functions and an average dimensionless wall distance $y^{+}$between 2.8 (for $R e=400$ ) and 11.25 (for $R e=$ 3000). In general, their numerical results differ from the experimental results by $10 \%$ to $16 \%$. Gullapalli and Sundén [8] performed simulations of fluid flow throughout the channel of a plate heat exchanger with several different corrugation angles, and added an inlet and outlet connection to create similar inlet or outlet conditions as in the laboratory experiment. They used the LRR-IP (Reynolds Stress) turbulence model. They performed several calculations with different boundary conditions on the wall of the plate when calculating heat transfer (e.g. constant heat flux, constant wall temperature, etc.). The results of the heat transfer calculations were $20 \%$ to $30 \%$ and the pressure differences were $10 \%$ to $35 \%$ below the values from the laboratory experiment. Nonetheless, they found CFD to be a useful tool in the relative comparison of the various shapes of the heat plates, for detection of possible poorly constructed geometric details of corrugation, and the determination of velocity profiles inside of the channels. Tiwari et al. [9] analysed a case using CFD tools, with two channels in which a fluid with a nanoparticle (nanofluid) flowed counter-current. They also used a - turbulence model in the study. They also carried out a laboratory experiment with the same configuration of the plate heat exchanger elements as they used in the numerical calculation, with the latter results differing from the experimental results by a maximum of $3.75 \%$. Lee and Lee [10] performed non-stationary CFD analyses using the large eddy simulation (LES) approach on a small part of a fish bone heat plate heat exchanger. They found oscillations in the flow at a turbulent flow regime, which increase the heat transfer and also increase the pressure drop. Sarraf et al. [11] carried out laboratory and CFD analyses of two-channel sample. They compared numerical results with the results obtained with a thermal camera, where they recorded the exterior of the plate pack during laboratory experiments. The temperature distribution difference between CFD results and experimental results was within $10 \%$. They obtained the results with a $k-\varepsilon$ turbulence model. They also tried to analyse the channel flow with a $k-\omega$ turbulence model, but were not successful due to convergence problems. They distinguished two types of fluid flow, ,helical“ and „cross" flow, that coexists in the channels formed by the fish bone patterned heat plates. Helical flow appears in direction from the inlet to outlet passing grooves while cross flow appears along the groove. Which flow prevails depends on the mass flow and the angle between the grooves on the heat plate. Piper et al. [12] presented a numerical study of a pillow plate heat exchanger using a plate with a periodic pillow-like pattern. They found that fluid flow in such a channel is characterized by two distinct areas - the meander core, which is crucial for heat transfer, and the recirculation zone that occurs behind the welded joint and reduces the efficiency of the heat exchanger. They suggested several possible solutions to improve the efficiency of such heat exchanger, which could increase efficiency by up to $37 \%$. In numerical analysis, they used a domain derived from a transformation simulation. The domain was a small part of the entire channel which, however, repeats periodically throughout the volume. They simplified 
the calculation with all possible symmetries. They used the $k-\varepsilon$ turbulence model and constant heat flux as a boundary condition on the domain wall. In a study presented by Yogesh et al. [13] investigating the influence of pipe geometry in a tubular heat exchanger with cooling fins, authors used $k-\omega$ turbulence model instead of the commonly used $k-\varepsilon$ turbulence model to obtain results that were more consistent with their reference. For the $k-\omega$ turbulence model, the results were $5.2 \%$ and $6.6 \%$ lower than the reference ones, unlike the $k-\varepsilon$ turbulence model results where the difference was $26.9 \%$ and $44.8 \%$. Al zahrani et al. [14] performed a numerical analysis of a plate heat exchanger with five plates, two channels on the warm side and two on the cold side. They also used a $k-\varepsilon$ turbulence model. They compared the numerical results with the experimental ones obtained by Muley and Manglik [15]. The deviations were $\leq 10 \%$.

As mentioned above, despite the fact that numerous investigations were conducted on chevron plates heat exchanger, no literature on dimple pattern heat exchanger can be found. In our study, we have analysed the fluid flow in a channel formed by dimple pattern heat plate numerically. The obtained results were validated with laboratory results. These were obtained by newly developed measuring method, which allows direct comparison.

\section{NUMERICAL ANALYSIS OF FLUID FLOW}

\subsection{Channel Geometry Modeling}

The three- dimensional (3D) model of the heat plate was obtained by 3D scanning of the real plate. Onesixteenth of the cell was cut from the scanned $3 \mathrm{D}$ model. With the microscope measuring system, we also determined the appropriate shape of the brazing point and transferred it to the $3 \mathrm{D}$ model. The whole-cell model was created by mirroring over the corresponding edges. Symmetric cell was then multiplied by mirroring to obtain the desired numerical domain.

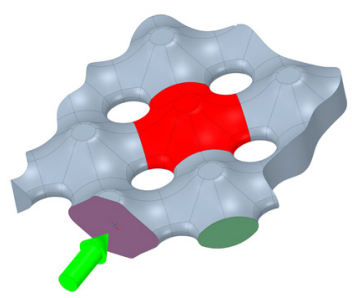

Fig. 2. Cell model (red) and part of the channel; green arrow indicates flow direction, domain inlet is darker, cell inlet/outlet is dark green
The geometry presented in Fig. 3 was made from the base cell, which served as a basis for modelling narrower or wider domains. The number of cells in basic geometry is 28 . When referred on e.g. $14 \times 2$ cells means 14 successive cells in direction and 2 parallel cells in $x$ direction. During the study, it was shown that due to the uniform velocity distribution at the inlet surfaces (darker in Fig. 2), the fluid flow in the first few cells was not yet developed to such an extent that it could be considered as representative. Similar things happen in the last few cells. For the aforementioned reasons, rather than for longitudinal periodic boundary conditions, we decided to extend the domain to the maximum number of consecutive cells in which we still obtained useful results using various turbulence model, that is 14 consecutive cells. For longer domains, this was not possible. There is an extension at the end of the geometric model to prevent backflow at the outlet surface.

The analysis of the impact of width of the numerical domain on the simulation result was performed on domains that also have a length of 14 cells, the widths of which are presented in Fig. 3. Domains with multiple parallel cells (2, 3 and 6) have the same amount of inlet and outlet surfaces, each outlet has an extension. When we refer to water velocity in this article, we refer to the average velocity of water through the largest cross-section of the cell, which is equal to the area of one inlet or outlet surface of the domain.

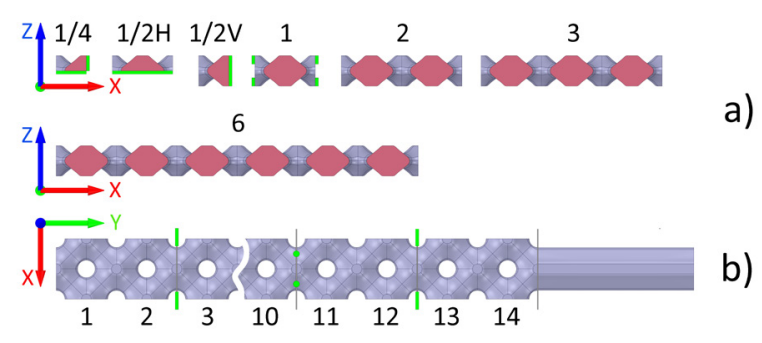

Fig. 3. The basic geometry of the domain with numbering of: a) narrower or wider domain, and b) successive cell

\subsection{CFD Simulation}

The CFD simulation was performed using the commercial Ansys Fluent 19.2 CFD software, which operates on the finite volume method. The turbulent flow was modelled using Reynolds-averaged NavierStokes equations (RANS). Reynolds stresses were calculated using Realizable $k-\varepsilon$ turbulence model with Enhanced wall treatment (EWT) wall function (hereinafter $k-\varepsilon$ ) and $k-\omega$ SST turbulence models 
(hereinafter $k-\omega$ ) [16]. The coupling between velocity and pressure was performed using a coupled scheme. During calculations, we monitored the change in significant quantities such as: residuals, area average velocity through the area between the $12^{\text {th }}$ and $13^{\text {th }}$ cell (Fig. 3b), area average pressure between the $2^{\text {nd }}$ and 3 rd cell (Fig. 3b), the maximal $y^{+}$on the wall and velocities in left and right points, (Fig. 3b, green points between $10^{\text {th }}$ and $11^{\text {th }}$ cell).

The basic relations for the motion of incompressible fluid are the continuity and momentum equations [16]:

$$
\begin{gathered}
\frac{\partial \rho}{\partial t}+\nabla \cdot(\rho \vec{u})=S_{m}, \\
\frac{\partial}{\partial t}(\rho \vec{u})+\nabla \cdot(\rho \vec{u} \vec{u})=-\vec{\nabla} p+\nabla \cdot(\overline{\bar{\tau}})+\rho \vec{g}+\vec{F} .
\end{gathered}
$$

The dimensionless distance between the mesh node closest to the wall and the wall is presented by the equation [16]:

$$
y^{+}=\frac{\rho \Delta y u_{\tau}}{\mu}
$$

where

$$
u_{\tau}=\left(\frac{\tau_{\omega}}{\rho}\right)^{\frac{1}{2}} .
$$

The domain was divided into seven elements. Planes which divided the elements were positions on which the results were monitored. This is shown in Fig. 3b. The lines in the figure represent the planes on which the area average pressure was monitored. The difference in pressures on one element, on two cells, was then calculated by subtracting the pressure at the beginning of the element from the pressure at the end of the element. Thus, we obtained a pressure difference (pressure drop) on all individual domain elements. These results of the pressure difference were compared with those obtained through laboratory experiments.

\subsection{Mesh Generation}

The mesh was created in Ansys Fluent (with Fluent meshing) software environment. During research, the flow conditions inside the described geometry were proved to be challenging. Knowing this, we implemented a polyhedron mesh. Tests have shown that calculations with polyhedral meshes need up to four times fewer elements, half the computational memory and one-tenth to one-fifth of the computational time compared to tetrahedral meshes to achieve the same accuracy [17]. In addition to the aforementioned properties, during the research, it was also found that a convergent solution cannot be easily achieved by a tetrahedron mesh. Taking this into account we conducted a mesh density independence study. We produced ten different mesh densities, which are presented in Table 1 (number of finite volumes is valid for basic domain presented on Fig. $3 b)$. In Table 1 there is also data for maximal $y^{+}$for each mesh density at different velocities.

Table 1. Mesh properties for basic domain

\begin{tabular}{lcccc}
\hline \multirow{2}{*}{ Mesh } & $\begin{array}{c}\text { No. of finite } \\
\text { volumes }\end{array}$ & \multicolumn{3}{c}{ Maximal $y^{+}$at different velocities } \\
\cline { 3 - 5 } & $0.2 \mathrm{~m} / \mathrm{s}$ & $0.45 \mathrm{~m} / \mathrm{s}$ & $0.7 \mathrm{~m} / \mathrm{s}$ \\
\hline M1 & 107126 & 1.3 & 2.3 & 3.4 \\
\hline M2 & 143829 & 1.4 & 2.5 & 3.4 \\
\hline M3 & 183973 & 1.3 & 2.4 & 3.3 \\
\hline M4 & 270753 & 1.0 & 1.9 & 2.6 \\
\hline M5 & 533612 & 0.5 & 1.0 & 1.3 \\
\hline M6 & 743587 & 0.6 & 0.9 & 1.2 \\
\hline M7 & 1158886 & 0.5 & 0.8 & 1.1 \\
\hline M8 & 1464905 & 0.6 & 0.9 & 1.2 \\
\hline M9 & 2408576 & 0.5 & 0.8 & 1.1 \\
\hline M10 & 5372272 & 0.5 & 0.7 & 1.0 \\
\hline
\end{tabular}

Average $y^{+}$for the mesh M4 using the $k-\varepsilon$ based turbulence model is 1.01 at the velocity of $0.7 \mathrm{~m} / \mathrm{s}$. Using $k-\omega$ based turbulence model, $y^{+}$is on the same level. The ratio of maximal to average $y^{+}$is approximately 2.6 and is maintained in all cases.

\subsection{Boundary Conditions}

In practice, the water velocity in the channel is between $0.2 \mathrm{~m} / \mathrm{s}$ and $0.7 \mathrm{~m} / \mathrm{s}$. For the calculations, where we checked the adequacy of the mesh and the computational model and thus the consistency of the calculated results with measurements, we used velocities between $0.2 \mathrm{~m} / \mathrm{s}$ and $0.7 \mathrm{~m} / \mathrm{s}$ for the inlet boundary condition. The considered flow was singlephase, incompressible, stationary, three-dimensional, and turbulent. Working fluid is water with constant physical properties (water at temperature $15.2{ }^{\circ} \mathrm{C}$ ). Natural convection and radiation are neglected. The symmetry boundary conditions were determined for the $14 \times 1 / 4,14 \times 1 / 2 \mathrm{H}, 14 \times 1 / 2 \mathrm{~V}$ and $14 \times 1$ domains. The $14 \times 2,14 \times 3$, and $14 \times 6$ domains do not have symmetry boundary conditions applied (if $14 \times 1$ cells means domain with 14 successive cells with extension as presented in Fig. 3 b, $14 \times 3$ cells would mean that there are three main domains bonded in parallel). The surfaces on which the symmetry boundary conditions 
were determined are indicated in green in Fig. 3a under marks for $1 / 4,1 / 2 \mathrm{H}, 1 / 2 \mathrm{~V}$ and 1 where results were obtained with, as well as without symmetry.

\section{EXPERIMENTAL ANALYSIS OF FLUID FLOW}

The test bench shown in Fig. 4 consists of a frequency-controlled pump that drives the water in a closed circuit, an expansion vessel that maintains a uniform water pressure, a flowmeter, a water tank, a cooling heat exchanger to maintain the temperature of the water during the measurement and a large vessels (LV) assembly with sample and gauge pressure and pressure drop sensor. The LV assembly consists of two large stainless-steel vessels. These are built in the same way, with exception that one has an opening for installing the temperature sensor. In use, however, they are facing each other so that the test sample can be clamped to them, as shown in Figs. 4 and 5. At the inlet and/or outlet, respectively, the flow rectifier is installed with the purpose to direct the flow of water towards the walls of the vessels, thereby mixing the water inside and preventing a portion of the flow from having direct access to the inlet surfaces of the test sample, which could cause uneven flow to the inlet surfaces of the test sample. At the same time, water with a homogeneous temperature is obtained throughout the whole volume. The temperature sensor is positioned in the centre of the vessel and measures the temperature at which water enters the sample. The pressure is measured on the wall of the vessel as shown in Fig. 4. The pressure drop sensor is mounted on the edge of the vessels where no vortices are expected, in order to provide a stable pressure measurement. Because the fluid flow is extremely slow in the vessels, the pressure field is also homogeneous. This way, the same inlet conditions are ensured on all inlet surfaces of the sample.

The measurements were performed at discrete points at $0.2 \mathrm{~m} / \mathrm{s}, 0.3 \mathrm{~m} / \mathrm{s}, 0.4 \mathrm{~m} / \mathrm{s}, 0.45 \mathrm{~m} / \mathrm{s}, 0.5 \mathrm{~m} / \mathrm{s}$, $0.6 \mathrm{~m} / \mathrm{s}$, and $0.7 \mathrm{~m} / \mathrm{s}$ average water velocity through the inlet surfaces. At each point, a steady state was established and the data of all measured values was simultaneously recorded for $30 \mathrm{~s}$ at a frequency of $5 \mathrm{~Hz}$. The result is the average of all measured quantities. We also carried out measurements of the pressure drop at a different water temperatures, which were $15.2{ }^{\circ} \mathrm{C}, 16^{\circ} \mathrm{C}, 18{ }^{\circ} \mathrm{C}, 20^{\circ} \mathrm{C}$ and $25^{\circ} \mathrm{C}$ with the maximum standard deviation of temperature $0.19^{\circ} \mathrm{C}$. Measurements of pressure drop at $15.2{ }^{\circ} \mathrm{C}$ were performed on three samples of 19 cells (inlet surfaces) of width and 31, 24 and 16 consecutive cells long, respectively.

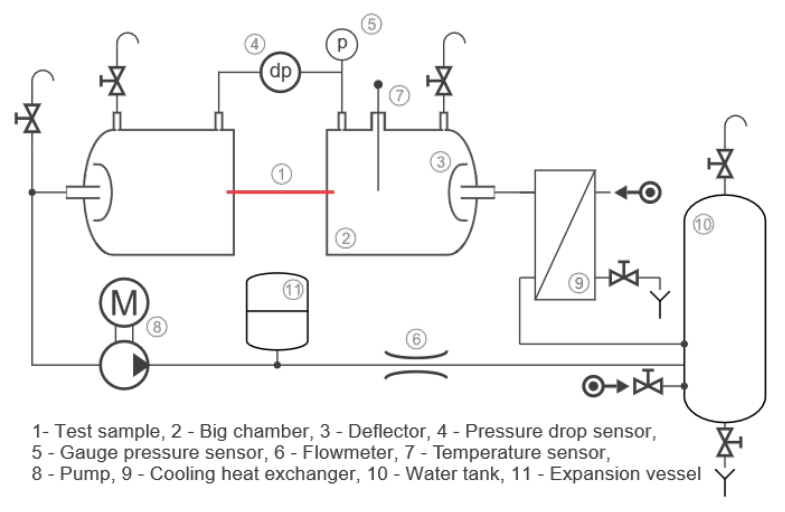

Fig. 4. Test bench scheme

The measurement uncertainty of the results for flow is $1 \%$, the pressure drop is $1 \%$ and the temperature is $0.3{ }^{\circ} \mathrm{C}$.

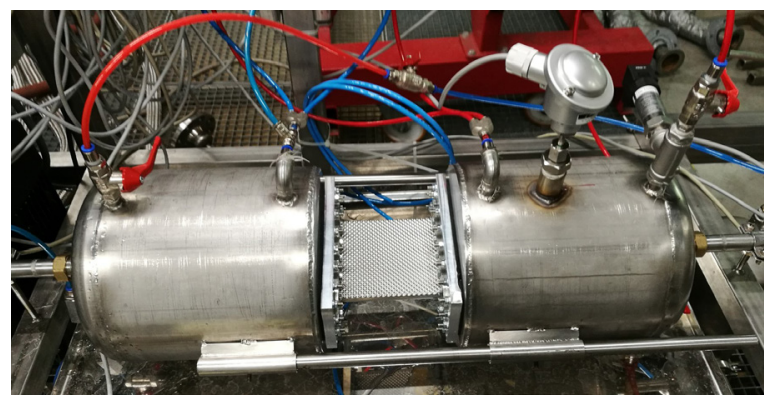

Fig. 5. Photo of the large vessel assembly with the test sample during the measurement

\section{RESULTS AND DISCUSSION}

As described, we conducted a mesh density independence study for 10 different meshes with 3 boundary conditions for two turbulence models $(k-\varepsilon$ and $k-\omega)$. Fig. 6 shows the dependence of the simulation results on the mesh density for the area average pressure drop between $9^{\text {th }}$ and $10^{\text {th }}$ cell marked on Fig. 3b. The mesh number 4 (M4) with 270753 finite volumes is used as a reference in this graph.

The entire XB12L heat plate has about 1500 dimple cells, which means that it is necessary to economically choose the density of the mesh with which to calculate solutions that will cover conditions in the whole channel in the future, or even in several channels of the considered heat exchanger. In our case, we decided to perform the calculations with the density of M4 shown in Fig. 6, which means about 10000 finite volumes per dimple cell. This is a manageable number of mesh elements, and the difference from the mesh independent solution is a 
reasonable $3 \%$ to $4 \%$ for both turbulence models and for all velocities in the channel. The only difference is the $k-\omega$ solution at $0.7 \mathrm{~m} / \mathrm{s}$, which no longer follows other solutions at mesh densities $>6$.

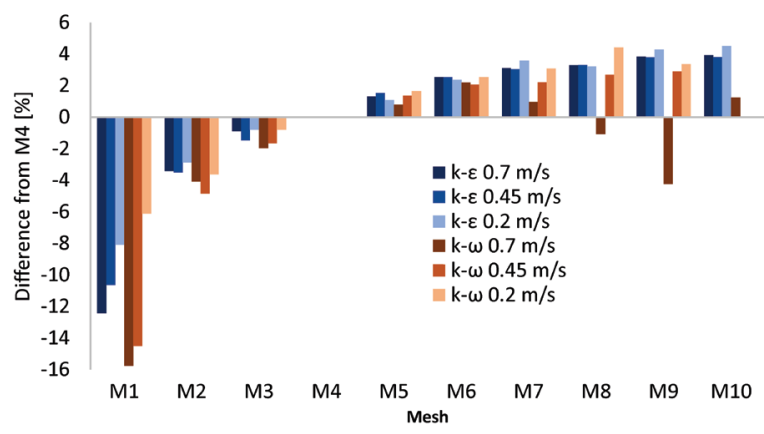

Fig. 6. Dependence of numerical results on mesh density

Fig. 7 shows the dependence of the domain width on the results of pressure drop (Fig. 3). As a reference, in this graph the $k-\varepsilon$ turbulence model uses a $14 \times 3$ domain and the $k-\omega$ turbulence model a $14 \times 1$ domain. In Fig. 3, the green line indicates the surfaces where symmetric boundary conditions were used.

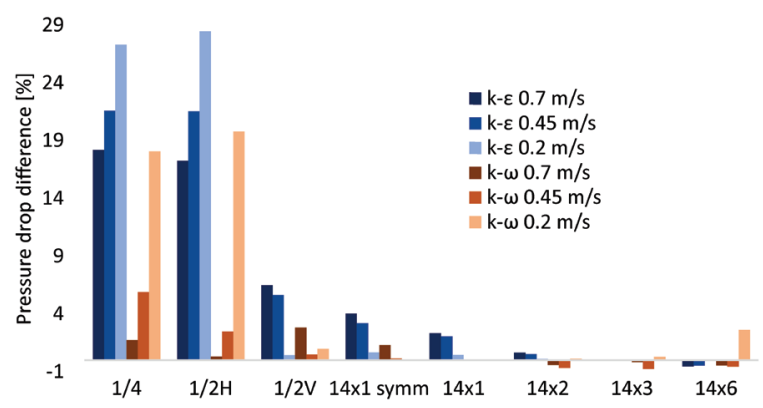

Fig. 7. Dependence of numerical result on domain width

Numerical results analysis showed that the use of $k-\varepsilon$ turbulence model requires the use of a domain with three parallel cells in our case $14 \times 3$ domain (Fig. $3 \mathrm{a}$, no. 3), and for $k-\omega$ turbulence model, one cell type is sufficient (Fig. 3a, no. 1). From the graph in Fig. 7, it can be seen that the predicted results for the domains $1 / 4$ and $1 / 2 \mathrm{H}$ (that is for those two cells in which the cells are cut horizontally) are showing pressure drop which is significantly too high. Slightly better results are obtained for vertically sectioned cells, the $1 / 2 \mathrm{~V}$ domain, where the results are still high for $k-\varepsilon$ and closer to the measurement results for $k-\omega$ turbulence model. It is interesting to note that the results for the " $14 \times 1$ symm" domain, where symmetry was used as the wall boundary condition, are worse than for the same domain where we did not use symmetry boundary condition. The domain geometry in this part was defined as a wall on which, like everywhere else on the wall, a boundary layer mesh was built. With the $k-\varepsilon$, the result is slightly different with the expansion of the domain, but then stabilizes. The $14 \times 3$ domain was chosen as the most appropriate. However, with the $k-\omega$ turbulence model, the result does not change with the expansion of the domain. Therefore, the $14 \times 1$ domain was chosen as the most suitable one. Fig. 8 shows the dependence of the pressure drop result on the distance (number of cells) from the inlet surface (Fig. 3). As a reference, the result on cells 9 and 10 is used in this graph.

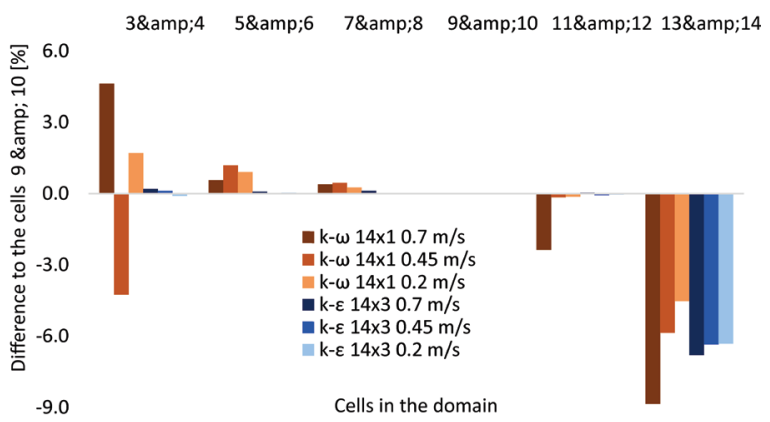

Fig. 8. Dependence of the result of the pressure drop on the domain length

As mentioned above, the pressure difference along the domain varies slightly due to the inlet and outlet boundary conditions. It stabilizes satisfactorily on cells between 7 and 10 as shown in Fig. 8 . Therefore, the pressure difference on cells 9 and 10 was chosen for validation.

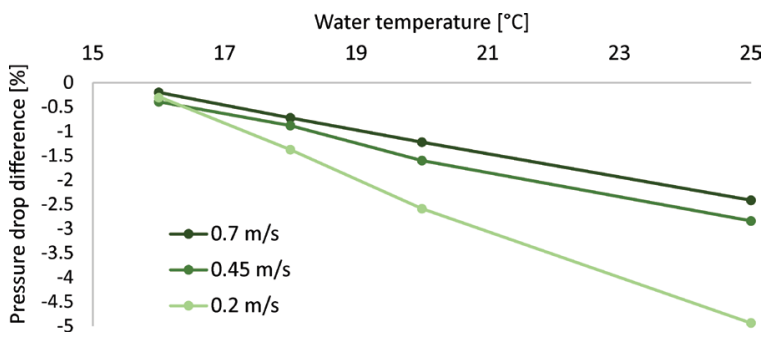

Fig. 9. Dependences of measurement result on water temperature in laboratory measurement

Pressure drop is also a function of water temperature, so a laboratory analysis was performed to evaluate the dependence of pressure drop on temperature. Measurements required for this analysis were conducted with the measuring method as described in chapter 2. Fig. 9 shows the dependence of the result of pressure drop on the water temperature of the laboratory measurement. The water temperature at $15.2^{\circ} \mathrm{C}$ is used as a reference in this graph. It can 


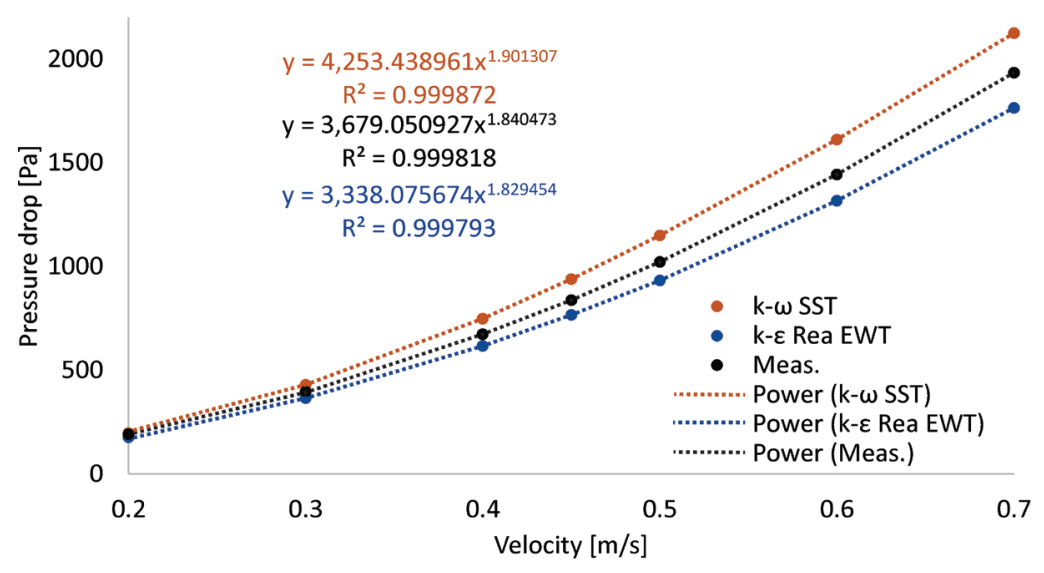

a)

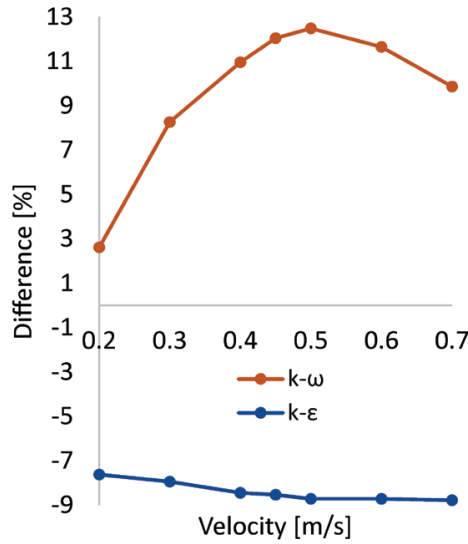

b)

Fig. 10. a) Measurement and CFD results with associated power-law function, and b) relative difference between laboratory measurements and different numerical solutions of $k-\varepsilon$ and $k-\omega$ turbulence models

be seen that the dependence in this domain is expected to be linear and also that the deviation increases nonlinearly as water flow decreases. The uncertainty of the measured pressure drop due to temperature deviation during the measurement is significantly lower than $0.5 \%$.

Black colored curve in Fig. 10 on the left chart shows the results of laboratory measurements on a sample of $31 \times 19$ cells. As CFD results, also laboratory measurements are presented for two consecutive cells calculated by dividing the measured pressure drop result with 31 and multiplied by 2 . There are also results from CFD calculations obtained by using $k-\varepsilon$ (blue) and $k-\omega$ (orange) turbulence model as presented above. All curves have associated powerlaw functions. In Fig. 10b chart shows the relative difference between numerical calculations and laboratory results, where results on abscissa contain the results of said laboratory measurements.

Fig. 11 shows the relative difference between the calculated values (from the regression equations) and the laboratory measurements or CFD calculations.

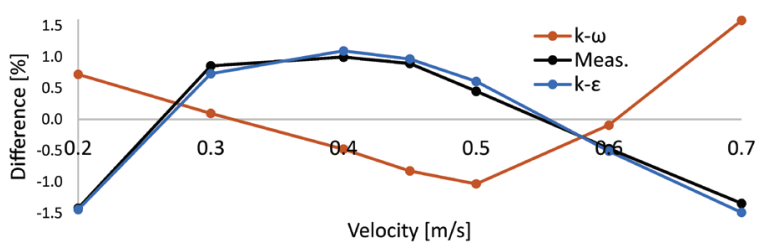

Fig. 11. Relative difference between calculated values (from regression equations) and laboratory measurements or CFD calculations
The results of laboratory measurements on samples with lengths of 24 and 16 cells are not presented in this paper. However, the results of pressure drop for a sample with 24 cells are on average about $1 \%$ higher and for a sample with 16 cells about $2 \%$ higher than for the longest sample. The difference increases as the flow decreases. We selected the results for the longest sample as the most appropriate one. Due to the deliberate design of mounting the sample into the test bench, it can be assumed that the pressure conditions at each individual inlet (or outlet) surface are the same. Therefore, the water velocities are the same in all parts of the sample. The influence of the wall on the pressure drop is negligible in relation to the relatively large width of the test sample. Also, the influence of possible temperature inhomogeneity of water in the sample is neglected. However, the influence of the sample length is not negligible. We could assume that the fluid flow in a large vessel is completely laminar. It is laminar also just before it enters the sample. Even when it enters the cells, the flow does not immediately turn completely to fully developed turbulent flow, but it does require some cells. Although the exact length of this inlet region remains unknown, we can say that it is the same for all samples. It can also be said that the pressure drop in this region is larger than with the fully developed turbulent flow inside the sample. Thus, the influence of the inlet region on the pressure drop per cell in the short sample is greater than in the longer one. In this way, we can explain why the pressure drop per cell increases with the shortening of the samples. 
The graph in Fig. 10a shows relatively nice curves, which also match the corresponding power-law functions, indicating that the laboratory measurements and numerical calculations were performed correctly. How well the power-law functions fit with the measured data or CFD calculations is shown in the graph in Fig. 11. We can conclude that all values are within the interval $\pm 1.6 \%$.

From the graph in Fig. 10a, we can see that the $k-\varepsilon$ on average predicts an $8.4 \%$ lower pressure drop compared to the measured values. This difference is approximately the same in the entire area considered, which can be clearly seen from the graphs in Fig. 10b and in Fig. 11. The results of numerical calculations with the $k-\omega$ turbulence model predict an average difference of $9.7 \%$ in pressure drop compared to the results of laboratory measurements. This difference is not constant, but varies with speed, as can be seen from the graph in Fig. 10b. The agreement with the power curve is in a similar ratio to the measurements but with the opposite shape, which can be seen in the graph in Fig. 11.

Fig. 12 shows the volume of domain in which the velocity of water is positive in the $y$-direction (that is in the direction from inlet to outlet). The volume in the Fig. 12a is prediction of the calculation with $k-\varepsilon$ and the volume in the Fig. 12b is prediction of the calculation with the use of $k-\omega$ turbulence model. Zone where the velocity in the $y$-direction is positive was named "live zone", zone where the velocity in the $y$-direction is negative was named "dead zone". The shape of "live zone" can be seen on Fig. 12.

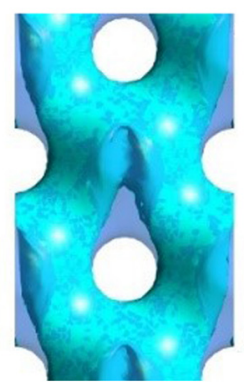

a)

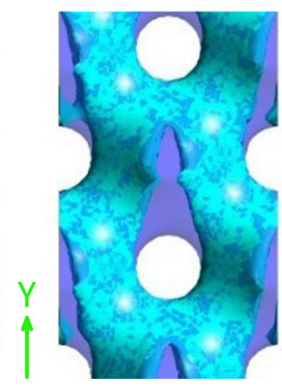

b)
Fig. 12. The volume of the domain in which the velocity of water in the $y$-direction is positive: a) $k-\varepsilon$, and b) $k-\omega$

From the Fig. 10b we can see that the use of the $k-\omega$ turbulence model predicts on average 19.8 $\%$ greater pressure drop than the prediction from model where $k-\varepsilon$ was used. This may also be because the $k-\omega$ turbulence model predicts a significantly different "dead zone" behind the brazing point as could be seen in Fig. 12. The "dead zone" prediction of $k-\varepsilon$ turbulence model is not only different in shape, it is also significantly smaller when compared with prediction of $k-\omega$ turbulence model. The "dead zone" is $22.3 \%$ of whole volume for the model when $k-\varepsilon$ turbulence model was used and $31.6 \%$ of the whole volume when the $k-\omega$ turbulence model was used. The size of the "dead zone" practically does not change with velocity in the analysed velocity range.

In our case, use of the $k-\varepsilon$ turbulence model (in the case of steady-state simulation) proved to be a robust and reliable tool for predicting the pressure drop in the analysed geometry under consideration. We had no major convergence problems, no matter what mesh density we used for calculations. This is also evidenced by the study in which we determined the dependence of the result from the computational mesh density, where the results are smoothly limited to the true value (Fig. 6). Even along with the domain, the result does not change significantly (Fig. 8), and as a result, the domain could be significantly shorter, which in turn means a shorter computation time or a higher mesh density and thus a better result. The results at different velocities behave similarly to the measurement results (Figs. 10 and 11). It yielded useful results comparable to those of laboratory measurements.

With the use of the $k-\omega$ turbulence model we did not obtain solutions for long samples, because they behave unexpectedly with increasing mesh density, the results along the domain are unusual, and the results behave differently at different velocities than the measurement results (Figs. 10 and 11). It seems that with use of the $k-\omega$ turbulence model we have obtained fairly unreliable results. However, it must be understood that the flow (at given velocities in the channel) is turbulent. This can be assured with certainty, since the relation between the pressure drop and the flow rate is not linear, which would mean laminar flow.

With the increase of mesh density, the solution approaches the true value due to the higher resolution in solving the equations, but there are more and more problems with convergence, which indicates a strongly turbulent flow, which in the densest mesh becomes too intense and the time independent solution finally fails.

It can be concluded that steady-state simulations with $k-\omega$ turbulence model are not suitable for predicting the pressure drop in analysed heat exchanger. However, this means that in this case the $k-\varepsilon$ turbulence model is a safe choice to predict 
pressure drop in channels formed by dimple pattern heat plate.

\section{CONCLUSIONS}

In this article, we have presented a comprehensive analysis of the flow state in a plate heat exchanger with a dimple pattern heat plate structure. The research was conducted in two interrelated fields: laboratory and numerical. We carried out several laboratory measurements of the channel that makes up the XB12L. The methodology of work was developed and the result was a completely new methodology for conducting laboratory measurements with the socalled large vessels. This measurement method has yielded the results we can trust. A similar method of performing measurements on a heat exchanger channel cannot be found in the literature. We have found that the fluid flow in the channel under consideration is turbulent at all velocities considered. In the numerical part of the research, we have determined the optimal mesh density, which has a very favourable relationship between the accuracy of the results and the consumption of computer resources. We have determined the optimal numerical domain size for use of different turbulence models.

We have found that in steady-state simulations use of $k-\varepsilon$ realizable turbulence model with Enhanced wall treatment is more appropriate than use of the $k-\omega$ SST turbulence model.

Future research will cover the implementation of time-dependent simulations and introducing energy equations for heat transfer in numerical work, and by completing laboratory test bench in a way that allows the measurement of heat transfer.

\section{NOMENCLATURES}

$F \quad$ External body forces, [N]

$g$ Gravitational acceleration, $\left[\mathrm{m} / \mathrm{s}^{2}\right]$

$p$ Pressure, $[\mathrm{Pa}]$

$u$ Velocity, $[\mathrm{m} / \mathrm{s}]$

$S_{m}$ Mass added to the continuous phase, [kg]

$u_{\tau} \quad$ Velocity at a distance $\Delta y,[\mathrm{~m} / \mathrm{s}]$

$\Delta y$ Distance from the wall, [m]

$y^{+}$Dimensionless distance from the wall, [-]

$\mu \quad$ Dynamic viscosity, $[\mathrm{kg} /(\mathrm{ms})]$

$\rho$ Density, $\left[\mathrm{kg} / \mathrm{m}^{3}\right]$

$\tau_{\omega} \quad$ Wall shear stress, $[\mathrm{Pa}]$

$\overline{\bar{\tau}} \quad$ Stress tensor $[-]$

\section{REFERENCES}

[1] Fernandes, C.S., Dias, R.P., Maia, J.M. (2008). New plates for different types of plate heat exchangers. Recent Patents on Mechanical Engineering, vol. 1, no. 3, p. 198-205, Dol:10.217 4/2212797610801030198.

[2] Kandlikar, S.G., Grande, W.J. (2003). Evolution of Microchannel flow passages - Thermohydraulic performance and fabrication technology. Heat Transfer Engineering, vol. 24, no. 1, p. 3-17, 2003, D0I:10.1080/01457630304040.

[3] Focke, W.W., Knibbe, P.G. (1986). Flow visualization in parallelplate ducts with corrugated walls. Journal of Fluid Mechanics, vol. 165, p. 73-77, D0l:10.1017/S0022112086003002.

[4] Metwally, H.M., Manglik, R.M. (2004). Enhanced heat transfer due to curvature-induced lateral vortices in laminar flows in sinusoidal corrugated-plate channels. International Journal of Heat and Mass Transfer, vol. 47, no. 10-11, p. 2283-2292, 2004, D0I:10.1016/j.jijheatmasstransfer.2003.11.019.

[5] Kanaris, A.G., Mouza, A.A., Paras, S.V. (2005). Flow and heat transfer in narrow channels with corrugated walls a CFD code application. Chemical Engineering Research and Design, vol. 83, no. 5, p. 460-468, D0l:10.1205/cherd.04162.

[6] Han, X.H., Cui, L.Q., Chen, S.J., Chen, G.M., Wang, Q. (2010). A numerical and experimental study of chevron, corrugated-plate heat exchangers. International Communications in Heat and Mass Transfer, vol. 37, no. 8, p. 1008-1014, D0l:10.1016/j. icheatmasstransfer.2010.06.026.

[7] Gherasim, I., Galanis, N., Nguyen, C.T. (2011). Heat transfer and fluid flow in a plate heat exchanger. Part II: Assessment of laminar and two-equation turbulent models. International Journal of Thermal Sciences, vol. 50, no. 8, p. 1499-1511, DOI: 10.1016/j.ijthermalsci.2011.03.017.

[8] Gullapalli, V.S., Sundén, B. (2014). CFD simulation of heat transfer and pressure drop in compact brazed plate heat exchangers. Heat Transfer Engineering, vol. 35, no. 4, p. 358366, DOI:10.1080/01457632.2013.828557.

[9] Tiwari, A.K., Ghosh, P., Sarkar, J., Dahiya, H., Parekh, J. (2014). Numerical investigation of heat transfer and fluid flow in plate heat exchanger using nanofluids. International Journal of Thermal Sciences, vol. 85, p. 93-103, D0l:10.1016/j. ijthermalsci.2014.06.015.

[10] Lee, J., Lee, K.-S. (2014). Flow characteristics and thermal performance in chevron type plate heat exchangers. International Journal of Heat and Mass Transfer, vol. 78, p. 699-706, D0I:10.1016/j.ijheatmasstransfer.2014.07.033.

[11] Sarraf, K., Launay, S., Tadrist, L. (2015). Complex 3D-flow analysis and corrugation angle effect in plate heat exchangers. International Journal of Thermal Sciences, vol. 94, p. 126138, D0I:10.1016/j.jithermalsci.2015.03.002.

[12] Piper, M., Zibart, A., Tran, J.M., Kenig, E.Y. (2016). Numerical investigation of turbulent forced convection heat transfer in pillow plates. International Journal of Heat and Mass Transfer, vol. 94, p. 516-527, D0l:10.1016/j. ijheatmasstransfer.2015.11.014.

[13] Yogesh, S.S., Selvaraj, A.S., Ravi, D.K., Rajagopal, T.K.R. (2018). Heat transfer and pressure drop characteristics of inclined elliptical fin tube heat exchanger of varying ellipticity ratio using CFD code. International Journal of 
Heat and Mass Transfer, vol. 119, p. 26-39, D0l:10.1016/j. ijheatmasstransfer.2017.11.094.

[14] Al zahrani, S., Islam, M.S., Saha, S.C. (2019). A thermohydraulic characteristics investigation in corrugated plate heat exchanger. Energy Procedia, vol. 160, p. 597-605, DOI:10.1016/j.egypro.2019.02.211.

[15] Muley, A., Manglik, R.M. (1999). Experimental study of turbulent flow heat transfer and pressure drop in a plate heat exchanger with chevron plates. Journal of Heat Transfer, vol. 121, no. 1, p. 110-117, D0l:10.1115/1.2825923.

[16] ANSYS Inc. (2018). ANSYS Fluent Theory Guide, Release 19. ANSYS Inc., Canonsburg.

[17] Peric, M., Ferguson, S. (2005). The advantage of polyhedral meshes, CD-adapco. Melville. 